\title{
O Programa de Aquisição de Alimentos (PAA) em Cuiabá-MT na ótica da Nova Economia Institucional
}

\section{The Food Acquisition Programme (FAP) at Cuiabá-MT from the perspective of the New Institutional Economics}

Geni Cecília Figueiredo do Carmo Mello - Mestre em Agronegócios e Desenvolvimento Regional (UFMT, 2011), professora Assistente do Departamento de Ciências Contábeis da UNEMAT em Cáceres-MT. E-mail: genimello2009@hotmail.com

Adriano Marcos Rodrigues Figueiredo - Doutor em Economia Aplicada (UFV, 2002); professor da Faculdade de Economia da UFMT, em Cuiabá-MT. E-mail: adriano@ufmt.br

\section{Resumo}

O Programa de Aquisição de Alimentos (PAA), em Cuiabá-MT, foi analisado na ótica da nova economia institucional quanto à operacionalização e metas; resultados produtivos; e eventuais dificuldades ou imperfeições na gestão. Fez-se análise estatística das variáveis tecnológicas assim como produção e área, comparando-se grupos dos participantes e dos não participantes do PAA. Os resultados indicaram que o programa estava sendo executado com algumas dificuldades ou imperfeições devido à sua estrutura de governança. As metas do programa foram avaliadas tanto no âmbito do "MDS-Prefeitura" como de "MDSCONAB". Houve diferença favorável ao grupo do PAA quanto à participação em organizações. Não existiu diferença na produção média entre os grupos participantes e não participantes; e foram detectados filtros institucionais em ambos os níveis de análise.

\section{Palavras-chave}

Agricultura Familiar. PAA. NEI. Mato Grosso.

\section{Abstract}

The Food Acquisition Programme (FAP) in the city of Cuiabá-MT was analyzed from the perspective of the New Institutional Economics as operation and targets; productive results; and any difficulties or failures in management. There was statistical analysis of variables such as production and area, comparing groups of participants and non participants in the FAP. The results indicated that the program was running with difficulties or failures due to its governance structure. The program goals were evaluated under both the "MDS-Prefeitura" as "MDSCONAB". There were differences in favor of the group of PAA regarding participation in organizations. There was no statistical difference in average production among the participating groups and non-participants; and institutional filters were detected at both levels of analysis.

\section{Keywords}

Family Farming. PAA. NIE. Mato Grosso. 


\section{INTRODUÇÃO}

Estudos têm apontado que a agricultura familiar vem despontando como modelo alternativo de desenvolvimento para o meio rural. Abramovay (2000), em seu estudo sobre desenvolvimento rural, ressalta que a agricultura familiar também é reconhecida como agente dinamizador da economia local. Ele destaca a importância dos agricultores familiares, através da capacidade de inovação, assim como da sua interação com as instituições locais, no desenvolvimento local.

Nessa linha de raciocínio, a agricultura, principalmente a familiar, torna-se um importante instrumento para que ocorra desconcentração de renda, geração de divisas, criação de ocupações produtivas, aumento da produtividade e da qualidade e diversificação e verticalização da produção. Isso se justifica ao analisar o impacto que o segmento familiar representa no total dos estabelecimentos rurais. Segundo o Censo Agropecuário de 2006, aproximadamente 85\% do total de propriedades rurais do país pertenciam a grupos familiares, cuja área média era de 18,37 hectares. Outro resultado apontado pelo Censo é o número de pessoas ocupadas na agricultura: 12,3 milhões de trabalhadores no campo estão em estabelecimentos da agricultura familiar, que representa $74,4 \%$ do total de ocupados no campo (IBGE, 2009). Ou seja, de cada dez ocupados no campo, sete estão na agricultura familiar, que emprega 15,3 pessoas por 100 hectares, contribuindo, assim, para uma forma de produção onde haja no campo um desenvolvimento, e não somente um crescimento (BRAVO, 2002).

Diante da importância do segmento da agricultura familiar para o desenvolvimento local, políticas públicas vêm sendo traçadas. Segundo Veiga (2002), importantes medidas estão sendo tomadas para beneficiar o segmento familiar, dentre elas destacam-se: a desapropriação de terras e o crédito fundiário, que foram responsáveis por um aumento de mais de 15\% na área de agricultores familiares em menos de uma década.

Simultaneamente, houve outra ação que veio fortalecer ainda mais esse segmento, através de cinco linhas de crédito do PRONAF: crédito de custeio e investimento, infraestrutura e serviços públicos, assistência técnica e extensão, capacitação e comercialização (VEIGA, 2002, p. 6).

Ainda objetivando um avanço maior para a agricultura familiar, surge o Programa de Aquisição de Alimentos (PAA) em julho de 2003, através da Lei Federal no 10.696 , de 2 de julho de 2003, cuja finalidade é comprar alimentos e recompor os estoques públicos.

Outro ponto importante a ser observado é que a agricultura familiar estabelece várias relações com a segurança alimentar. A mais lembrada é como 
provedora de alimentos para a sociedade. Porém, a importância da agricultura familiar para a segurança alimentar vai além da produção primária. Sua característica de distribuição de renda e geração de empregos possibilita que milhões de pessoas tenham acesso a alimentos.

Assim, as formas sob as quais os alimentos são produzidos e ofertados determinam as condições de acesso a eles, e isto por alguns motivos como: estruturas concentradas que conferem poder de mercado a poucos agentes econômicos, como as grandes corporações agroalimentares e as redes de supermercados; e, também, ao fato de estas estruturas dificultarem ou mesmo impedirem a reprodução em condições dignas de um amplo conjunto de pequenos e médios empreendimentos rurais e urbanos, constituindo-se fator de iniquidade social e, portanto, de insegurança alimentar (RIO GRANDE DO SUL, s.d.).

Cuiabá, capital do estado de Mato Grosso, possui uma população de 551.250 habitantes, (IBGE, 2010), densidade demográfica de 156,27 habitantes por $\mathrm{km}^{21}$. A população urbana corresponde a $541.002(98,12 \%)$ habitantes e a rural 10.348 (1,88\%). Portanto, possui muitos consumidores de alimentos e prováveis potenciais compradores dos produtos oriundos da agricultura familiar.

Conforme registro da EMPAER, de abril de 2009, existiam no município de Cuiabá 1.687 agricultores familiares, distribuídos da seguinte forma: Comunidades tradicionais: 30 propriedades, com 719 famílias; Assentamentos de reforma agrária do Instituto Nacional de Reforma Agrária (INCRA/MT): uma comunidade com 35 famílias; Assentamentos de reforma agrária do Instituto de Terras de Mato Grosso (INTERMAT): 5 comunidades, com 691 famílias; Assentamentos de agrários via Crédito Fundiário: 18 comunidades, com 242 famílias (EMPAER, 2009). Observa-se que as comunidades tradicionais representam 42,62\% dos agricultores familiares desse município, seguidos de perto por assentados de reforma agrária do INTERMAT (40,96\%), e 14,34\% representam assentados via Crédito Fundiário.

Devido à importância da agricultura familiar no contexto nacional, o governo federal vem atuando de forma concreta para melhorar as condições desse segmento, através de implementação de programas e facilitação no acesso ao crédito. Dessa forma, uma política que vem sendo importante para a agricultura familiar é o PAA, como citado acima. Através do programa, alimentos são adquiridos de agricultores familiares que se enquadram no Programa Nacional de Fortalecimento da Agricultura Familiar (PRONAF), e destinados à formação de estoques de segurança ou canalizados para populações em situação de risco

\footnotetext{
Habitantes e densidade demográfica de 156,27 hab./km2 seguno Censo Demográfico 2010.
} 
alimentar. Portanto, o programa torna-se um fortalecedor do mercado interno, pois eleva o poder aquisitivo da população rural; melhora a dieta das famílias e garante a demanda dos alimentos produzidos na agricultura familiar.

Vários estudos têm evidenciado os benefícios do PAA brasileiro, em várias regiões do país, podendo citar Chmielewska, Souza e Lourete (2010), Chmielewska (2009), Muller (2007), Schmitt (2005), e Delgado et al. (2005). Entretanto, na maioria das vezes, as análises não envolvem o estado de Mato Grosso.

Em Cuiabá-MT, especificamente, não se têm estudos publicados sobre o assunto. A modalidade do PAA operado no município de Cuiabá é a de Compra Direta Local da Agricultura Familiar (CDLAF), "Compra para Doação Simultânea", cujo objetivo é a compra de alimentos produzidos por agricultores familiares e a doação desses alimentos para entidades integrantes da rede socioassistencial.

Para analisar a política pública "Programa de Aquisição de Alimentos (PAA) executado no município de Cuiabá", optou-se por utilizar o referencial teórico da Nova Economia Institucional (NEI), através dos seus fundamentos: ambiente institucional, estrutura de governança, filtros institucionais, dentre outros.

Diante dessa realidade, o problema desta pesquisa foi assim formulado: Como acontece a escolha de produtores, beneficiários e produtos no Programa de Aquisição de Alimentos? A hipótese geral é que existem dificuldades operacionais relacionadas com os filtros institucionais de primeiro nível que delimitam a escolha entre os agentes e os produtos contemplados.

Nessa diretriz, este trabalho tem por objetivo geral investigar a operacionalização do PAA em Cuiabá. Para isso, pretende atingir os seguintes objetivos específicos: a) Avaliar o cumprimento das metas do PAA no município; b) Comparar resultados produtivos entre produtores participantes do PAA e não participantes; c) Averiguar eventuais dificuldades ou imperfeições na execução do programa; e, d) Contribuir com sugestões de melhoria do programa.

Como hipóteses secundárias, associadas aos objetivos específicos, têm-se: a) O programa não vem cumprindo as metas estabelecidas para o município de Cuiabá; b) A produção média entre os grupos participantes e não participantes do PAA não é diferente; c) O grau de participação em organizações comunitárias como associações ou cooperativas é diferente entre os participantes e não participantes do PAA; d) Em relação à utilização de técnicas modernas como assistência técnica, irrigação e outras, existem diferenças de emprego entre os produtores que participam do PAA e aqueles que não participam; e, e) Existem 
filtros institucionais que interferem na escolha de quem participa entre os produtores e entre os beneficiários, assim como dos produtos.

\section{MUNICÍPIO DE CUIABÁ-MT}

Cuiabá foi fundada em 8 de abril de 1719 . Apresenta área total $3.538,17 \mathrm{~km}^{2}$, correspondendo 254,57 $\mathrm{km}^{2}$ à macrozona urbana (Lei, n. 4.719/04) e 3.283,60 $\mathrm{km}^{2}$ à área rural. A população, segundo Censo Demográfico 2010, (IBGE, 2010), é de 551.250 habitantes e densidade demográfica de 156,27 hab. $/ \mathrm{km}^{2}$. A população urbana corresponde a $541.002(98,12 \%)$ habitantes e a rural $10.348(1,88 \%)$. Faz limite com os municípios de Chapada dos Guimarães, Campo Verde, Santo Antônio de Leverger, Várzea Grande, Jangada e Acorizal. É um entroncamento rodoviário-aéreo-fluvial e o centro geodésico da América do Sul, nas coordenadas $15^{\circ} 06$ '56", 80 de latitude sul e 5606'05', 55 de longitude oeste.

Garcia (2003), através da documentação pesquisada, traz uma estimativa das dietas alimentares (dieta alimentar padrão), de acordo com as necessidades dos habitantes da província à época (1800-1840). Assim, a dieta média recomendada era: "farinha de milho 300g; feijão 150g; arroz 150g; milho (cozido) 30g; mandioca (cozida) 50g; farinha de mandioca 10g; banana (crua) 60g; abóbora (cozida) 30g; carne bovina 110g; carne de caça 20g; toucinho 30g; carne de peixe 30g; carne de aves 30g" (GARCIA, 2003, p. 78).

Percebe-se que a dieta predominante da época era reflexo da cultura indígena, e de acordo com dados apresentados sobre a alimentação nesse período, verifica-se que existe grande ligação com os alimentos produzidos atualmente pelo segmento da agricultura familiar no município de Cuiabá. Dessa forma, esses produtos ainda representam a maioria dos alimentos ofertados pelos agricultores para serem comercializados via PAA no município, pela Prefeitura (feijão, mandioca, farinha de mandioca, milho verde, abacaxi, melancia, banana, abóbora, maxixie, couve, alface), e pela Conab (abóbora, banana, berinjela, mamão, maxixe, malancia, melão, milho verde, pepino, quiabo, mandioca).

Quanto à agricultura, neste município, conforme registro do censo agropecuário de 2006, dos 1.311 estabelecimentos rurais, 1.031 dentre estes são de agricultura familiar, representando $78,64 \%$ do total; 280 são estabelecimentos de agricultura não familiar (21,36\%). Quanto à área, os estabelecimentos de agricultura não familiar detêm 111.550 ha, que representa 88,98\% do total, enquanto que os de agricultora familiar estão distribuídos em 13.816 ha e, portanto, essa característica não difere do que acontece no estado e no Brasil, ou seja, há concentração de terras. 
Quanto à produção de alimentos, a agricultura familiar é responsável pela produção de alimentos básicos como: mandioca (60,48\%), abacaxi (9,45\%), canade-açúcar (20,67\%), milho em grão (4,68\%), melancia (2,77\%), produtos típicos da lavoura temporária, que se compõem de 386 estabelecimentos familiares, e 58 não familiares. Já os produtos da lavoura permanente são: banana $(52,23 \%)$, cocoda-baía (5,87\%) e manga (41,97\%), cujos agricultores familiares representam 73 estabelecimentos e 44 são de não familiares (IBGE, 2009).

\section{O PROGRAMA DE AQUISIÇÃO DE ALIMENTOS (PAA): SEGURANÇA ALIMENTAR}

O Programa de Aquisição de Alimentos (PAA) é associado às políticas de Segurança Alimentar e Nutricional (SAN) da Secretaria Nacional de Segurança Alimentar e Nutricional (SESAN) do Ministério do Desenvolvimento Social e de Combate à Fome (MDS). Foi instituído pelo artigo 19 da Lei no 10.696, de 2 de julho de 2003, regulamentado pelo Decreto $n^{\circ}$ 5.873, de 15 de agosto de 2006. Apresenta-se como uma das ações do Fome Zero, e como importante inovação do Plano Safra 2003/2004. Tem por finalidade comprar alimentos e recompor os estoques públicos.

Os objetivos do PAA são: garantir o acesso aos alimentos em quantidade, qualidade e regularidade necessárias às populações em situação de insegurança alimentar e nutricional e promover a inclusão social no campo por meio do fortalecimento da agricultura familiar; melhoria da qualidade das refeições das entidades socioassistenciais; recomposição dos estoques públicos de alimentos.

Existem diferentes modalidades de acesso, como: a Compra Direta da Agricultura Familiar (CDAF), que permite a aquisição de produtos da agricultura familiar, para distribuição ou para formação de estoques públicos; a Compra para Doação Simultânea, que propicia a compra de alimentos produzidos por agricultores familiares e sua disponibilização para doação a entidades da rede de promoção e proteção social, e assume importante papel na promoção da segurança alimentar do público atendido; a Formação de Estoque pela Agricultura Familiar, que propicia aos agricultores familiares instrumentos de apoio à comercialização de seus produtos, sustentação de preços e agregação de valor à produção; a Aquisição de Alimentos que atende a merenda escolar, com base na Lei n ${ }^{\circ} 11.947 / 2009$, que determina a utilização de, no mínimo, 30\% dos recursos repassados pelo Fundo Nacional de Desenvolvimento da Educação (FNDE) para alimentação escolar, e compra de produtos da agricultura familiar. 
O PAA é desenvolvido com recursos dos Ministérios do Desenvolvimento Social e Combate à Fome (MDS) e do Desenvolvimento Agrário (MDA). As diretrizes do PAA são definidas por um Grupo Gestor, coordenado pelo MDS e composto por mais cinco ministérios: Fazenda; Planejamento Orçamento e Gestão; Agricultura, Pecuária e Abastecimento, representado pela Companhia Nacional de Abastecimento (CONAB); Desenvolvimento Agrário e Educação, representado pelo Fundo Nacional de Desenvolvimento da Educação (FNDE) (Figura 1).

Figura 1: Organograma de funcionamento do PAA (conselho gestor e instituições).

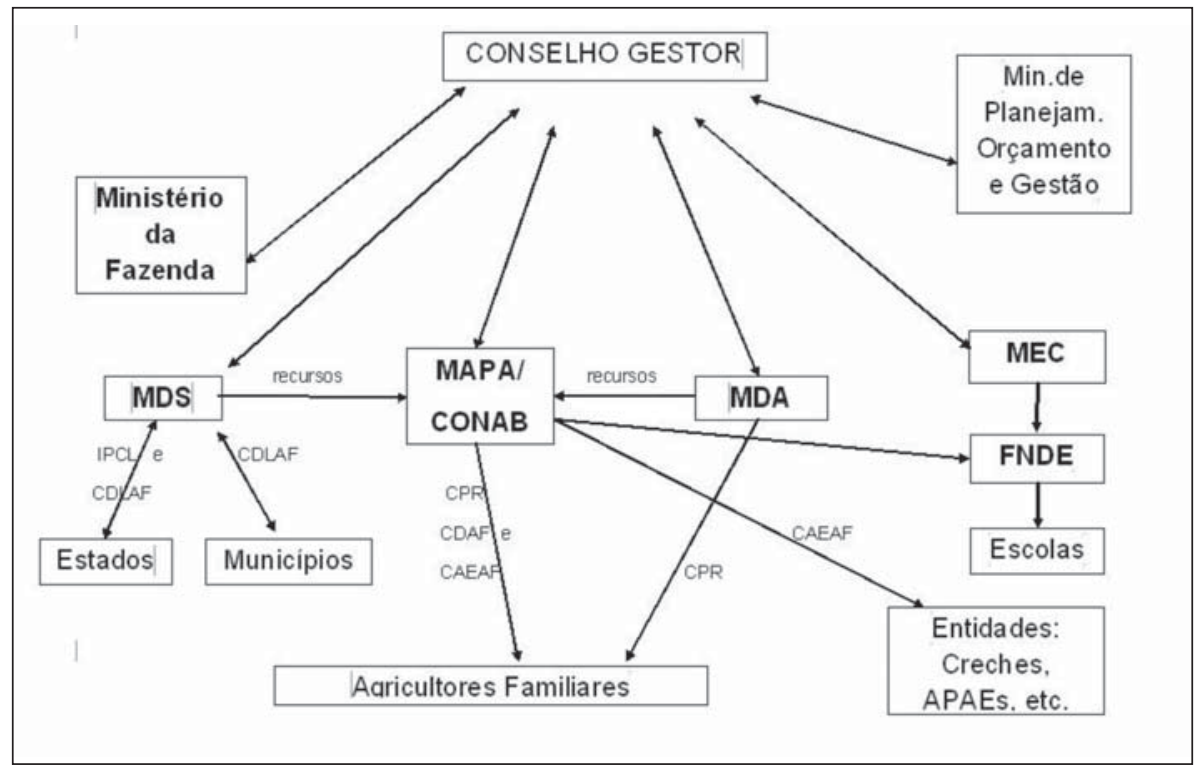

Fonte: Adaptado de Müller (2007).

Além do grupo gestor, podem ser incluídos os demais agentes, os quais configuram a rede de atuação do PAA: gestores executores: CONAB, estados, municípios; atores locais: conselhos, cooperativas, associações de agricultores familiares e entidades da rede socioassistenciais, conforme a Figura 2. 
Figura 2: Rede de atuação do PAA.

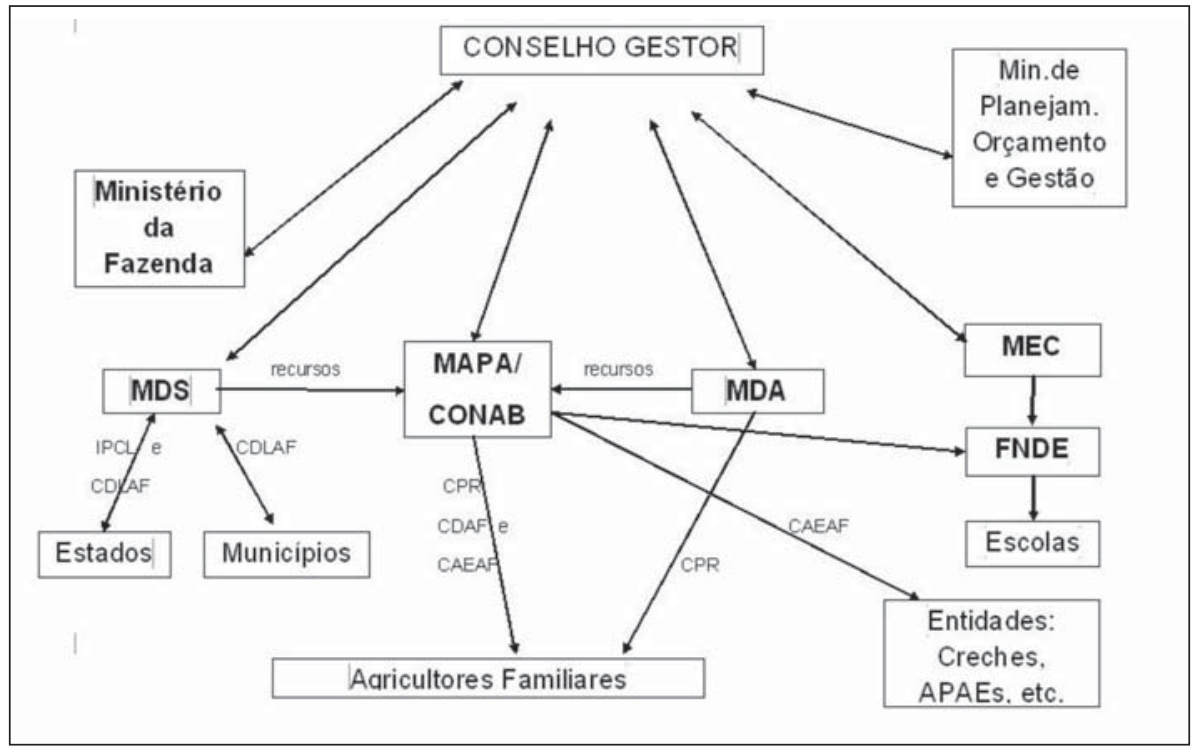

Fonte: Portal do MDS, MDA e CONAB (s.d.).

A rede de atuação de PAA possibilita a influência das instituições na formulação de políticas públicas. No caso, o Programa de Aquisição de Alimentos, como "regras do jogo" - os órgãos federais (o grupo gestor), e as organizações, como "jogadores" - as entidades que direta ou indiretamente fazem parte do processo (gestores executores e atores locais). Com a estrutura de governança (gestão) os atores envolvidos se relacionam para dirimir conflitos que por ventura venham a existir e solucionar problemas sobre assimetrias de informações. Portanto, percebe-se a importância da utilização dos fundamentos da Nova Economia Institucional na análise de atuação do PAA no município de Cuiabá.

\subsection{O PAA EM CUIABÁ}

A modalidade do PAA operado no município de Cuiabá é a de Compra Direta Local da Agricultura Familiar (CDLAF), "Compra para Doação Simultânea", cujo objetivo é a compra de alimentos produzidos por agricultores familiares e a doação desses alimentos para entidades integrantes da rede socioassistencial.

O Programa de Aquisição de Alimentos (PAA)/MDS foi realizado através de convênio entre o Ministério de Desenvolvimento Social e Combate à Fome, e a Prefeitura Municipal de Cuiabá - Convênio 177/2007, oriundo do Processo n. 71000.008006/2007-58, cujo objeto trata do apoio financeiro para implantar o 
Programa de Aquisição de Alimentos, através da CDLAF (Compra para Doação Simultânea), referente ao exercício 2007/2008, e teve seu prazo prorrogado por Termo Aditivo n. 01 ao Convênio n. 177/2007 até 30.09.2009.

Como objetivo, o Programa pretendia adquirir produtos de 240 (duzentos e quarenta) produtores da agricultura familiar do município de Cuiabá e distribuir esses produtos alimentícios a 175 (cento e setenta e cinco) entidades cadastradas no COMSEA, que participam dos programas sociais locais.

Figura 3: Organograma (informal) de funcionamento do PAA em Cuiabá.

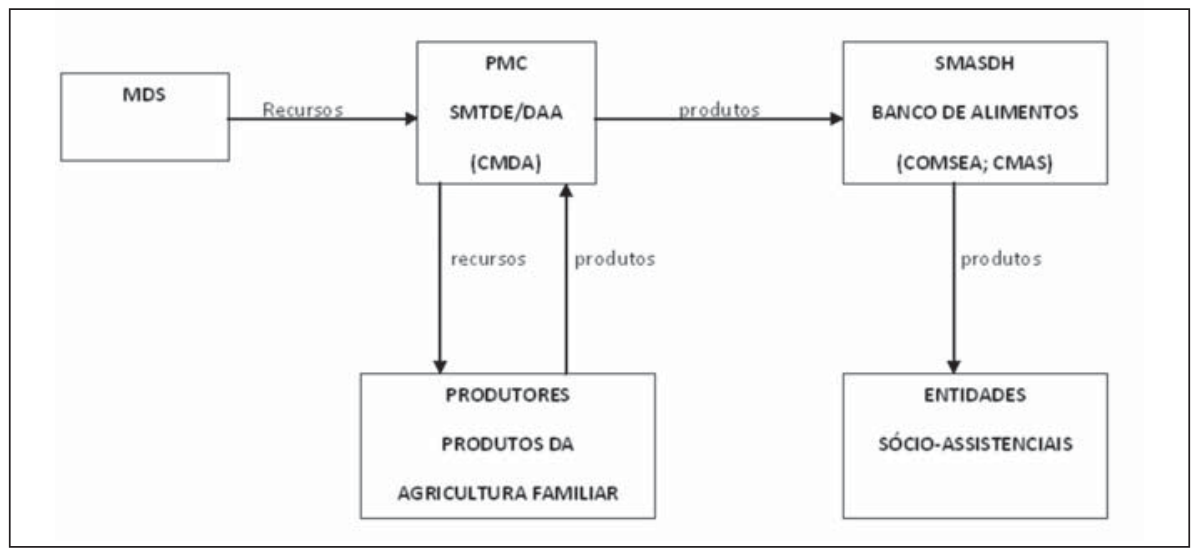

Fonte: elaborado pelos autores.

Através desse organograma informal de funcionamento (Figura 3) do PAA/ MDS/Prefeitura Municipal de Cuiabá, percebe-se como o arranjo institucional do PAA em Cuiabá vem sendo executado, isto é, o MDS firmou convênio com a Prefeitura de Cuiabá (regras formais) dentro do ambiente institucional e por outro lado existe a estrutura de governança - gestão de funcionamento do Programa em nível local, onde se identifica quem são os atores que direta ou indiretamente coordenam a execução do Programa (Secretaria Municipal de Trabalho e Desenvolvimento Econômico (SMTDE) - Diretoria de Agricultura e Abastecimento e Conselho Municipal de Desenvolvimento Agrário; Secretaria Municipal de Assistência Social e Direitos Humanos (SMASDH) - Conselho Municipal de Segurança Alimentar e Conselho Municipal de Assistência Social e Banco de Alimentos; Produtores e Entidades Socioassistenciais). Assim, verifica-se a influência das vertentes da NEI (ambiente institucional e estrutura de governança) na investigação: no Programa de Aquisição de Alimentos do município de Cuiabá, como se dá a escolha de quem participa entre produtores e entre os beneficiários, e a escolha dos produtos. 
Já o Programa de Aquisição de Alimentos (PAA)/CONAB foi realizado através de Termo de Cooperação nº 003/2009 (Processo n. 71000.036137/20090-7; vigência: 04.05.2009 até 31.07.2011), cujo objetivo é estabelecer parceria entre o Ministério de Desenvolvimento Social e Combate à Fome (MDS), e a Companhia Nacional de Abastecimento (CONAB).

$\mathrm{Na}$ proposta do PAA/Conab (Sureg/MT) o município de Cuiabá, através da comunidade Marcolana, constava a participação de 27 (vinte e sete) agricultores familiares, que forneceriam os seguintes produtos: abóbora paulista, abóbora menina, banana da terra, banana maçã, berinjela, mamão formosa, maxixe, melancia, melão caipira, milho verde em espiga com palha, pepino caipira, quiabo, mandioca in natura; e uma entidade - o Banco de Alimentos, o qual seria o responsável pela entrega dos alimentos às entidades socioassistenciais cadastradas.

Percebe-se, através da Figura 4, que os recursos vêem do MDS via CONAB-matriz após análise das propostas formalizadas pelas respectivas associações junto à CONAB/SUREG/MT, que, também, deverá ser aprovada pelo Conselho Nacional de Segurança Alimentar e Nutricional (CONSEA) em nível estadual ou Conselho de Alimentação Escolar (CAE), isso devido ao fato do Conselho Municipal de Segurança Alimentar não estar até o momento totalmente estruturado. Foi informado pela técnica da CONAB que a preferência nessa avaliação é que seja feita por um conselho municipal.

Figura 4: Organograma (informal) de funcionamento do PAA (MDS/CONAB) em Cuiabá.

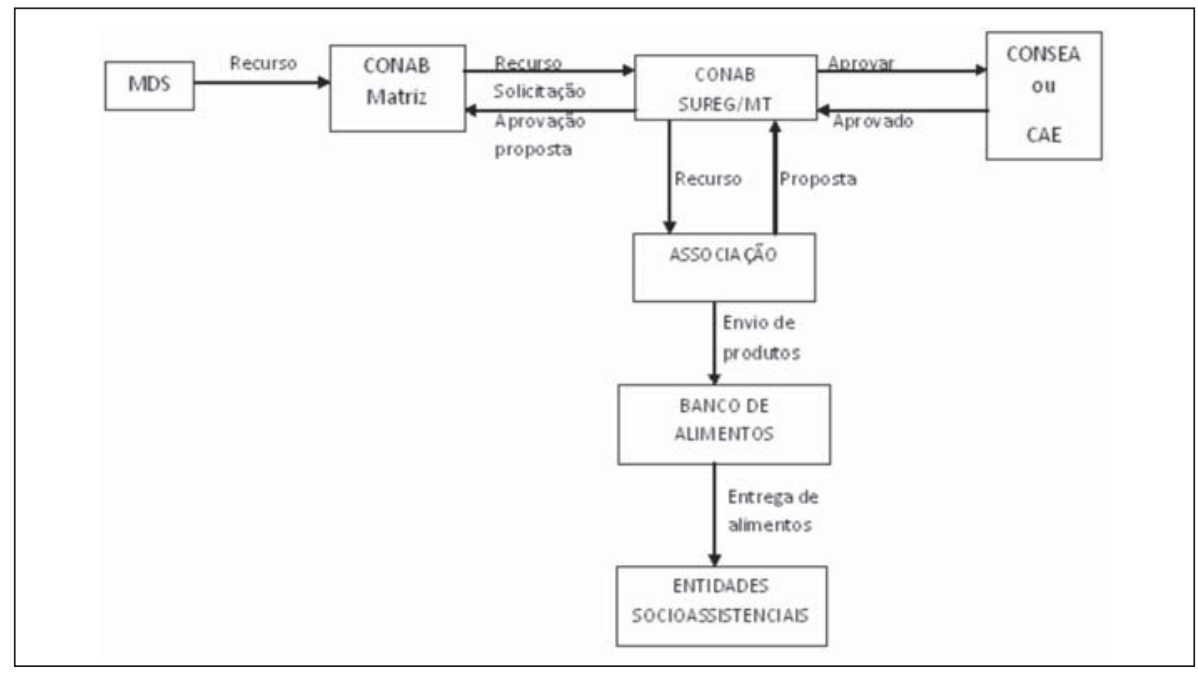

Fonte: elaborado pelos autores. 


\section{FUNDAMENTAÇÃO TEÓRICA}

A Nova Economia Institucional (NEI) surgiu nas décadas de 1960 e 1970, onde um grupo de economistas, dentre os principais destacam Ronald Coase, Oliver Williamson e Douglas North, começaram a se preocupar com aspectos micro e macroeconômicos das instituições.

Assim, a NEI trabalha com duas vertentes: primeiro o ambiente institucional (macroinstituições), onde se destacam: as regras formais (leis, políticas, regulamentação); regras informais (códigos de ética, laços familiares, valores culturais e étnicos); e direitos de propriedade da terra; e segundo as estruturas de governança (microinstituições) aquelas que regulam uma transação específica - custos de transação são definidos como o conjunto de regras: contratos entre particulares e normas internas às organizações (AZEVEDO, 2000).

Portanto, o conjunto de instituições econômicas e políticas formam a matriz institucional da sociedade. E a dinâmica evolutiva das economias surge da interação entre as instituições e as organizações, definidas como "os jogadores" (organização) que estão enquadradas nas "regras do jogo" (as instituições).

De acordo com Milani e Solínis (2002), a governança engloba a constituição de uma legitimidade do espaço público, a repartição do poder entre os que governam e os que são governados, os processos de negociação entre os atores sociais e a descentralização da autoridade e das funções ligadas ao ato de governar.

Dessa forma, a governança seria a prática pela qual se dá a gestão do desenvolvimento, prática na qual se dá um processo de acordo entre atores, pela formação e solução de conflitos e assimetrias, bem como pela constituição mínima de consensos. Estes elementos balizam a organização dos atores locais, ou seja, associações, cooperativas, ONG, entre outras organizações da agricultura familiar.

Portanto, ao se referir às instituições e à governança, procura-se trazer como exemplo o PAA que está sendo executado no município de Cuiabá, pois, existe uma estrutura de governança, como o conjunto de regras, o convênio entre o MDS e a Prefeitura de Cuiabá, que determina as normas que irão gerir o comportamento entre as partes: agricultores familiares, banco de alimentos, entidades socioassistenciais, conselhos, que por sua vez pode ocorrer a presença de filtros institucionais. Isso será analisado no decorrer da elaboração dessa pesquisa.

As regras formais são as mais evidentes no ambiente institucional, elas se materializam de diversas formas: a constituição, legislações complementares, conjunto de políticas públicas, dentre outros. No caso da agricultura, por exemplo, uma política de preços mínimos para o milho pode induzir agricultores 
a ampliar o seu cultivo, eventualmente em detrimento de culturas que concorrem pelos mesmos fatores de produção.

Essa análise pode ser vivenciada com o PAA, pois o governo se compromete em adquirir produtos agropecuários com recursos do MDS e/ou MDA, através de convênio, produzidos por agricultores familiares, dessa forma estes passam a ter segurança na comercialização de seus produtos por preços mais justos e garantindo renda para o segmento da agricultura familiar.

No entanto, o comportamento humano está condicionado, também, por regras informais, que são tão importantes quanto as formais. As regras informais consistem em valores, tabus, costumes, religiões, código de ética, laços étnicos e familiares, que representam o importante papel econômico de restringir o comportamento dos agentes. Assim, ao restringirem ações, instituições como estas podem facilitar as interações humanas, reduzindo os custos decorrentes da coordenação.

O PAA é um programa único, que se desdobra em diferentes modalidades, executadas por vários agentes operadores. Assim, algumas modalidades permitem o atendimento de agricultores familiares, organizados ou não em associações ou cooperativas, possibilitando, dessa forma, a constituição de diferentes tipos de arranjos institucionais, de acordo com a realidade de cada segmento, de tal forma que se podem aplicar os fundamentos da Nova Economia Institucional, tanto em níveis microinstitucionais, como macroinstitucionais, para entender se esse arranjo específico está permitindo a redução de risco de mercado, a garantia de preço e a comercialização aos agricultores familiares, agentes desse processo.

Estudos têm demonstrado que atores e organizações, orientados por um conjunto de regras formais (leis, normas, regulamentos etc.) e informais (tradições, hábitos, conduta ética etc.), constroem determinado mercado. Portanto, é importante entender como esses atores se interagem e quais as instituições (normas e convenções) estabelecidas nesse processo de construção, com objetivo de buscar um aperfeiçoamento contínuo desse ambiente institucional, através do estímulo da cooperação entre os atores, e o combate às incertezas.

Nesse enfoque é que a Nova Economia Institucional, através da aplicação dos seus conceitos, vem possibilitar uma melhor compreensão do funcionamento do mercado institucional do PAA adotado no município de Cuiabá, uma vez que esta abordagem privilegia a análise das regras (formais e informais) presentes no ambiente e como elas interferem na eficiência das organizações.

Para isso, as organizações devem intervir nas lacunas e imperfeições criadas pela racionalidade limitada e assimetria de informações dos agentes do mercado institucional do PAA. Mundo Neto e Souza Filho (2005) citam que 
essas lacunas e imperfeições criam filtros institucionais que acabam dificultando o alcance das metas do programa.

Assim, Zezza e Llambí (2001) utilizam do conceito de filtros institucionais: sistemas operacionais que podem danificar ou mesmo invalidar as regras definidas pelos gestores públicos aos agentes do mercado, para avaliar a eficácia das políticas públicas. Deste modo, os filtros institucionais trabalhariam como entraves para qualquer efetivação de normas e acordos entre indivíduos deste mercado, tornando ineficaz alguma política planejada.

Mundo Neto e Souza Filho (2005) apresentam três tipos de filtros institucionais, classificados como: primeiro nível (macro analítico); segundo nível (meso analítico); e o terceiro nível (micro analítico). Na sequência, descrevem-se as características de cada tipo de filtro.

Os filtros de primeiro nível estão relacionados ao desenho e à concepção da política, a partir desta oferta política transmitem-se os incentivos aos agentes, no tocante a preços, recursos produtivos e condições de trabalho.

Já o filtro de segundo nível, denominado filtro de "transmissão do incentivo", está vinculado ao comportamento e as regras criadas pelos agentes que participam do ambiente de operacionalização da política. Nesse caso, tratase da programação dos incentivos de preços e recursos produtivos para a efetiva produção, consumo e investimento.

O terceiro filtro institucional atua como nível de "tomada de decisão" e está relacionado com o comportamento dos atores que compõem o públicoalvo da política. No caso do PAA, estaria relacionado ao repasse da produção aos beneficiários das doações e aos aspectos finais de compra e doação entre produtores, CONAB e entidades beneficiadas.

Portanto, a ideia de usar os filtros institucionais e rede no acesso ao Programa de Aquisição de Alimentos ajuda a entender como funciona a gestão do PAA no município de Cuiabá: quem são os agentes envolvidos no processo (conselhos, sindicatos, associações); como se dá a escolha de quem participa entre os produtores, entre os beneficiários, escolha dos produtos, entre outros.

\section{METODOLOGIA E FONTE DOS DADOS}

A metodologia foi dividida em duas etapas: de obtenção dos dados (fase exploratória, dados secundários e dados primários) e de processamento e análise dos dados.

$\mathrm{Na}$ fase exploratória, buscou-se caracterizar o município de Cuiabá, objeto da pesquisa, como apresentado anteriormente. Além disso, buscou-se identificar 
documentos disponíveis e páginas eletrônicas da internet, com informações sobre Cuiabá no geral e sobre agricultura familiar, em especial.

Os dados secundários, bem como os documentos, foram obtidos junto aos órgãos oficiais estaduais e federais, como IBGE, secretarias de governo do estado de Mato Grosso, Prefeitura Municipal de Cuiabá, CONAB entre outros. Constam de informações sobre o perfil demográfico do município de Cuiabá, indicadores socioeconômicos, aspectos quantitativos da produção agropecuária e da agricultura familiar, além de informações sobre as demandas e ofertas de políticas públicas orientadas para a agricultura. A coleta de dados secundários foi complementada pela análise de documentos e diagnósticos já realizados sobre o município de Cuiabá.

Para atingir os objetivos propostos neste trabalho, foram utilizadas bases de dados provenientes de fontes diversas. Uma delas se trata de dados da Empresa Mato-grossense de Pesquisa, Assistência Técnica e Extensão Rural (EMPAER/ MT), referentes a 2009 .

Somado à análise dos indicadores quantitativos, foram coletados dados primários, através da aplicação de questionários nas 14 comunidades, compostas por 143 propriedades e realização de entrevistas semiestruturadas com atores locais, representantes da agricultura familiar e/ou de instituições relacionadas a este segmento. Os atores entrevistados foram escolhidos em amostra intencional segundo a ideia de agentes-chave, envolvendo: técnicos da SEDRAF-MT; técnicos da EMPAER; técnicos da Prefeitura Municipal de Cuiabá; Diretoria de Agricultura e Abastecimento do Município de Cuiabá; Asilo Santa Rita (entidade socioassistencial); Sindicato dos Trabalhadores Rurais de Cuiabá; Associação dos Agricultores Familiares da Comunidade Mineira; CONAB; Banco do Brasil; FETAGRI; produtores participantes e não participantes do PAA.

A seguir descrevem-se as variáveis tecnológicas e outras utilizadas na pesquisa:

a) Participação no Programa de Aquisição de Alimentos (PAA) - esse programa é importante como instrumento facilitador de aquisição direta de alimentos pelos órgãos públicos junto ao produtor familiar, portanto, impacta diretamente na garantia da comercialização dos produtos desses produtores com condição de pagamento de preço justo. A questão investigou a participação dos produtores familiares no PAA.

b) Participação em associação - trata-se de uma variável que funciona como instrumento de modificação social, ou seja, como um vetor que guia os produtores para obtenção de benefícios proporcionados em diversos programas 
(PRONAF, PAA e outros). A questão investigou a participação em associações, cooperativas e de outros tipos.

c) Acesso a assistência técnica - trata-se de instrumento fundamental de sucesso dos arranjos produtivos do município de Cuiabá, pois objetiva levar aos produtores familiares capacitação, através de palestras, seminários, orientações quanto à eficiência na utilização do solo, de acordo com as características do local, quanto às escolhas de sementes de qualidade, manejo integrado, controle de pragas e doenças, colheitas, armazenagem etc. A pergunta prevê a possibilidade de assistência via EMPAER, Prefeitura ou ainda empresas privadas.

d) Tipo de solo - também é importante conhecer o tipo de solo existente na região para que se tomem as decisões corretas quanto ao tipo de tecnologia a ser empregada, objetivando, claro, melhorar a produtividade da produção. A pesquisa investiga os tipos de solos existentes nas propriedades: arenoso, misto, argiloso e pedregoso.

e) Irrigação - trata-se de uma variável de suma importância, pois é um indicador que permite tecnologias alternativas para produção em diferentes momentos do ano. Essa variável permite que o produtor defina o que plantar e suas respectivas colheitas, principalmente nas épocas de entressafra. A questão identificou os seguintes tipos de irrigação: gotejamento, aspersão, sulco ou outra.

f) Energia elétrica - trata-se de uma das variáveis promotoras do desenvolvimento rural, tanto que contempla o programa Luz para Todos, do governo federal. Assim, essa variável, integrada com outras políticas de desenvolvimento rural, vem auxiliando para que aconteça desenvolvimento social e econômico, contribuindo dessa forma para a redução da pobreza. A questão identificou a existência ou não de energia elétrica nas propriedades.

g) Adubação - trata-se de variável importante, juntamente com o relevo, solo, irrigação, portanto, é a aplicação de nutrientes em quantidade e qualidade certas em época apropriada. A pergunta investigou que tipo de adubação os agricultores estão utilizando: adubação orgânica, adubação química ou se não faz adubação.

h) Conservação de solos - variável que demonstra a importância de se utilizar práticas conservacionistas, outra variável diretamente influenciada pela qualidade da assistência técnica juntos aos produtores rurais. A questão investigou se os agricultores adotam alguma prática que auxilia a conservação de solos: plantio em nível, curva de nível, terraços, ou se não fazem conservação de solo.

i) Mecanização - trata-se de variável importante na prestação de serviços na zona rural, ao analisar se as máquinas e implementos são próprios ou alugados. 
A mecanização da lavoura auxilia a aumentar a produtividade das terras. A questão identificou a forma de utilização da mecanização pelos agricultores familiares: máquina própria, máquina alugada ou não utilizam mecanização.

A análise estatística utiliza o teste $Z$ para as proporções de duas amostras (MCCLAVE; BENSON, 2009), quando se compara os participantes do PAA com os não participantes. Ou seja, testa-se a hipótese nula de que as proporções são iguais (equivalente a $\mathrm{H}_{0}: \mathrm{P}_{\text {PAA }}-\mathrm{P}_{\mathrm{NPAA}}=0$ : não existe diferença entre as proporções), hipótese alternativa $\mathrm{H}_{1}: \mathrm{P}_{\mathrm{PAA}}-\mathrm{P}_{\mathrm{NPAA}} \neq 0$ : existe diferença entre as proporções), para as variáveis: participação em associação; acesso a assistência técnica (se tem ou não, independente do órgão que a realiza); irrigação (dos diferentes tipos: gotejamento + aspersão + outras); energia elétrica; adubação (realizam adubação química, orgânica ou ambas); conservação de solos; análise de solo, agrotóxicos, mecanização (utilizam máquinas próprias ou alugadas).

Para comparar a quantidade produzida e a área plantada, utilizou-se um teste unilateral de distribuição de t de comparação das médias, sendo a hipótese nula de que as médias são iguais (H0: PAA = não PAA) e a hipótese alternativa de que a média dos participantes do PAA é superior a dos não participantes (H1: PAA> não PAA).

\section{RESULTADOS E DISCUSSÃO}

A proposta apresentada no âmbito do MDS-Prefeitura era que o programa atuasse em duas frentes: primeira: a produção com o escoamento do produto, e a segunda: o consumo com a suplementação alimentar às pessoas atendidas pelas entidades socioassistenciais. Assim, o objetivo era que 240 (duzentos e quarenta) produtores familiares participassem do programa, com 11 tipos de produtos, que beneficiassem 175 entidades socioassistenciais, as quais atenderiam diretamente 48.963 pessoas.

De acordo com o relatório de prestação de contas, referente ao convênio no. 177/2007 - Programa de Aquisição de Alimentos (PAA) - Modalidade: Compra Direta Local da Agricultura Familiar do Município de Cuiabá (CDLAF com doação simultânea), encaminhado ao Ministério de Desenvolvimento Social e Combate à Fome, tem-se que o número exato de produtores atendidos foi de 195 sem repetição, sendo que 17 produtores comercializaram seus produtos apenas em 2008, 72 em 2009, e 106 produtores comercializaram seus produtos em 2008 e 2009 com repetição de 106 agricultores perfazendo um total de 301 nomes beneficiados.

As instituições socioassistenciais beneficiadas foram as que estavam habilitadas através do cadastro no banco de alimentos com o número do CNPJ 
da instituição, o nome e CPF do responsável legal da entidade, número de pessoas atendidas. Foram atendidas 83 instituições, envolvendo escolas, creches, outros, mas sem a identificação precisa de quais.

Portanto, verifica-se que, a princípio, não foi cumprida a meta inicial do programa que era de apoiar 240 agricultores familiares por meio da compra de seus produtos, pois foram atendidos 195; e distribuir os produtos adquiridos aos beneficiários do programa, 175 entidades socioassistenciais, foram beneficiadas 83, com recursos no valor de $\mathrm{R} \$ 886.500,00$, sendo $\mathrm{R} \$ 840.000,00$ de repasse do concedente (MDS) e R \$46.500,00 de contrapartida do convenente (Prefeitura de Cuiabá), no período de novembro de 2007 a outubro de 2008. Como não foi cumprido, prorrogou-se por termo aditivo por mais um ano, até outubro de 2009. Assim, em 2009 houve a participação de mais 106 agricultores, com repetição, perfazendo um total de 301 nomes beneficiados, portanto, cumpriu-se a meta.

Verificando-se o Termo de Convênio nº ${ }^{\circ}$ 177/2007, percebe-se que existe certa fragilidade em relação à prestação de contas, no tocante aos produtos a serem entregues às instituições socioassistenciais, pois, de acordo com a cláusula segunda - dos deveres das obrigações, item 2.2 do convenente, subitem 2.2.6, diz:

[...] fornecer ao Concedente, trimestralmente, relatórios com o número de instituições beneficiárias e/ou beneficiários dos programas sociais que receberam os alimentos adquiridos, bem como o número de agricultores familiares apoiados e o valor médio do incentivo, em reais, por agricultor, e as toneladas de alimentos adquiridos.

Portanto, não é necessário ser informado nominalmente quais as instituições socioassistenciais que foram beneficiadas e nem os respectivos produtos doados, tornando-se difícil fazer um acompanhamento mais acurado sobre quais produtos realmente forem entregues e avaliar a qualidade dos mesmos. Esta fragilidade pode ser considerada um filtro institucional do Programa de Aquisição de Alimentos, pois se trata de lacunas e imperfeições que podem prejudicar o alcance das metas do programa.

Esse tipo de filtro pode ser considerado de primeiro nível, que segundo Mundo Neto e Souza Filho (2005), os filtros de primeiro nível estão relacionados ao desenho e concepção da política. Portanto, a fragilidade detectada na elaboração do convênio, ou seja, as lacunas existentes, no tocante à prestação de contas referentes à não obrigatoriedade de se informar nominalmente as instituições beneficiadas pelo programa e nem nominar os produtos entregues a estas, dá margem a falhas no monitoramento e avaliação da proposta, pois, não se 
consegue determinar com clareza quais as entidades que foram beneficiadas pelo programa e nem quais produtos foram entregues, muito menos sobre a qualidade dos mesmos. Isso contribui negativamente ao cumprimento do Princípio Constitucional da transparência que rege o Ente Público. Então, percebe-se, já neste momento, a existência de algumas dificuldades ou imperfeições na execução do PAA em Cuiabá.

Como foi mencionado, o PAA/CONAB foi realizado através de Termo de Cooperação n. 003/2009 (Processo n. 71000.036137/20090-7; vigência: 4.05.2009 até 31.07.2011), cujo objetivo é estabelecer parceria entre o Ministério de Desenvolvimento Social e Combate à Fome (MDS), e a Companhia Nacional de Abastecimento (CONAB).

O município de Cuiabá participou somente com a comunidade Marcolana, localizada no distrito do Aguaçu, através da assinatura da Cédula de Produtor Rural (CPR-DOAÇÃO), cujo projeto contemplava a participação de 27 famílias de agricultores familiares, com o fornecimento dos seguintes produtos: abóbora paulista, abóbora menina, banana da terra, banana maçã, berinjela, mamão formosa, maxixe, melancia, melão caipira, milho verde em espiga com palha, pepino caipira, quiabo e raiz de mandioca in natura. Havia a participação de uma entidade, o Banco de Alimentos, que ficaria responsável pela distribuição dos alimentos às entidades socioassistenciais cadastradas.

O período contemplado por esse convênio com a comunidade Marcolana teve início em 2009, porém sua execução aconteceu em outubro de 2009, com término previsto para outubro de 2010. No decorrer desse período houve a necessidade de prorrogação com termo aditivo de prazo para conclusão da proposta original, pois, até novembro de 2010, ainda faltava o valor de $\mathrm{R} \$ 4.913,76$ para concluir a proposta inicial que era de $\mathrm{R} \$ 114.391,50$ (valor líquido). Portanto, até junho de 2011, a comunidade Marcolana ainda não havia cumprido o acordo firmado na proposta original de 2009.

Percebe-se, também, que existe certa fragilidade no tocante à fiscalização por parte da CONAB, quanto à entrega dos alimentos, via Banco de Alimentos, às instituições socioassistenciais. Pois, foi informado pela técnica da CONAB/ MT, que esta regional não dispõe de técnicos suficientes para acompanhar in loco a distribuição dos alimentos às instituições cadastradas. Porém, foi informado, também, que a CONAB realiza reuniões uma vez ao ano com as instituições socioassistenciais, esclarecendo dúvidas do PAA, e como estas devem proceder ao receber os alimentos. Dessa forma, percebe-se que são as instituições que fiscalizam e denunciam quaisquer eventuais irregularidades em relação à qualidade 
ou entrega dos produtos elencados na proposta, através de denúncia anônima, reclamação via ouvidoria da $\mathrm{CONAB}$, entre outros meios.

Aqui, percebe-se que a CONAB-SUREG/MT não dispõe de técnicos suficientes para fiscalizar se os alimentos estão sendo entregues às entidades socioassistenciais, em quantidade e qualidade estipuladas no contrato, porém depara-se com uma estratégia adotada pela Conab (agente do processo) de realizar reuniões anuais com as entidades beneficiárias para informar sobre os objetivos, incentivos e benefícios do programa, de tal forma que essas entidades passam a ser as principais fiscalizadoras em relação à quantidade e qualidade dos produtos constantes do contrato. Aqui, verifica-se a existência do filtro institucional de segundo nível "transmissão do incentivo", que pode resultar em sucesso ou fracasso do programa. O convênio analisado usou desse filtro para o sucesso do programa.

As informações de entregas de produtos revelam que não ocorrem em todos os meses do ano, concentrados em janeiro, março, agosto, setembro, outubro e novembro de 2010. Esta entrega sem fluxo regular é outra fragilidade do programa, uma vez que as entidades beneficiadas enfrentam períodos sem entrega alguma. Este fato pode estar associado ao pequeno período de existência do programa na cidade, uma vez que este teve entregas apenas a partir de 2010 (MDS/CONAB) e ainda não houve estabilização das entregas. Em 2011, outra comunidade entrou no programa, mas ainda está no início das atividades.

Em análise da Cédula do Produtor Rural em questão, percebe-se que existe certa flexibilidade no prazo e na regularidade da entrega do produto, visto como desejável pelas entrevistas com agentes públicos, em face das incertezas da produção agrícola. Aqui, percebe-se a importância da estrutura de governança na flexibilidade de contratos firmados entre a CONAB e as associações e/ou cooperativas de agricultores familiares do município de Cuiabá, no caso específico, a comunidade Marcolana.

Diante da análise dos convênios, tanto em nível de município de Cuiabá, quanto com a CONAB, percebe-se que não existe uma preocupação maior com quem recebe os alimentos (entidades socioassistenciais), conforme descrito acima, configurando-se como fragilidade do programa ou filtro institucional de primeiro nível.

$\mathrm{Na}$ análise das proporções das amostras: participantes do PAA e os não participantes, tem-se o que segue. Estatisticamente, rejeita-se a hipótese nula (H0: não existe diferença entre as proporções dos grupos com respeito à realização de análise de solo) a 5\% de significância, ou seja, as proporções entre os participantes do PAA e os não participantes podem ser consideradas diferentes, pois, os que 
participam do PAA e fazem análise de solo é de 40\%; e dos que não participam e fazem análise de solo é de 58\%. Então, os não PAA usam mais análise de solo e pode ser considerada diferente $(z=-2,076$; prob. $=0,037)$.

Já, em relação à utilização de calcário, rejeita-se a hipótese nula (H0: não existe diferença entre as proporções dos grupos com respeito à utilização de calcário) a 5\% de significância, ou seja, as proporções entre os participantes do PAA e os não participantes podem ser consideradas diferentes, pois a proporção dos que participam do PAA que fazem uso do calcário é de 18\% contra 53\% dos não participantes e que usam o calcário. Então, os que participam do PAA usam menos calcário $(z=-4,33$; prob. $=0,000)$.

A análise estatística não permitiu rejeitar a hipótese nula (H0: não há diferença entre as proporções dos produtores participantes e não participantes do PAA com uso de irrigação) a 5\% de significância, ou seja, as proporções entre os participantes do PAA e os não participantes não pode ser considerada diferente, pois o grupo dos que participam do PAA e fazem irrigação são $72 \%$ e os do que não participam e fazem irrigação são $82 \%$ dos respectivos totais $(\mathrm{z}=-1,549$; prob. $=0,12)$.

Quanto ao uso de energia elétrica, em termos estatísticos, não se rejeita a hipótese nula (H0: não existe diferença entre as proporções dos grupos) a 5\% de significância, ou seja, as proporções entre os participantes do PAA e os não participantes não pode ser considerada diferente, pois o grupo dos que participam do PAA e usa energia é de $93 \%$ e os dos que não participam do PAA e usam energia é de $91 \%(z=0,439$; prob.=0,66).

Em relação à assistência técnica, estatisticamente, não se rejeita a hipótese nula (H0: não existe diferença entre as proporções dos grupos com respeito ao recebimento de assistência técnica) a 5\% de significância, ou seja, as proporções entre os participantes do PAA e os não participantes não pode ser considerada diferente $(z=-1,770$; prob. $=0,07)$. Entretanto, poderia rejeitar a hipótese nula a $10 \%$ de significância, ou $90 \%$ de confiança - a proporção dos não PAA é maior (67\%) contra 52\% para os participantes do PAA. O Programa (ATER) existe desde 2006, porém não existe infraestrutura adequada para seu funcionamento, os técnicos estão carentes de qualificação e os recursos financeiros são escassos para tocar o Programa dentro da finalidade proposta que é de levar aos agricultores familiares conhecimento técnico para elaboração de projetos e técnicas de gestão através de palestras, cursos, seminários, dentre outros.

Já em relação à utilização de agrotóxicos, estatisticamente, não se rejeita a hipótese nula (H0: não existe diferença entre as proporções dos grupos com respeito à utilização de agrotóxicos) a 5\% de significância, ou seja, as 
proporções entre os participantes do PAA e os não participantes não podem ser ditas diferentes, pois, o grupo dos que participam do PAA e usam agrotóxicos é de $88 \%$ e dos que não participam e usam agrotóxicos é de $84 \%$ $(\mathrm{z}=0,74$; prob. $=0,45)$.

Quanto à utilização de adubo, estatisticamente, não se rejeita a hipótese nula (H0: não existe diferença entre as proporções dos grupos com respeito à utilização de adubo) a 5\% de significância, ou seja, as proporções entre os participantes do PAA e os não participantes não pode ser ditas diferentes, pois o grupo dos que participam do PAA e utilizam adubo é de $85 \%$ e os dos que não participam e usam adubo é de $89 \%(z=-0,67$; prob. $=0,50)$.

$\mathrm{Na}$ utilização de técnicas para conservação de solo, estatisticamente, não se rejeita a hipótese nula (H0: não existe diferença entre as proporções dos grupos com respeito à utilização de técnicas para conservação de solo) a 5\% de significância, ou seja, as proporções não podem ser ditas diferentes, pois, o grupo dos que participam do PAA e fazem conservação de solo é de $96 \%$ e dos que não participam e fazem conservação de solo é de $91 \%(Z=1,28$; prob.=0,20).

$\mathrm{Na}$ mecanização, estatisticamente, rejeita-se a hipótese nula (H0: não existe diferença entre as proporções dos grupos com respeito à utilização de mecanização) a 5\% de significância, ou seja, as proporções entre os participantes do PAA e usam mecanização é de $91 \%$ e os que não participam e usam mecanização é de $98 \%$. Então, os não PAA usam mais mecanização e pode ser considerada diferente ( $\mathrm{z}=-2,058$; prob. $=0,039)$.

E na participação em associações, estatisticamente, rejeita-se a hipótese nula (H0: não existe diferença entre as proporções dos grupos com respeito à participação em associações) a 5\% de significância, ou seja, as proporções entre os participantes do PAA e os não participantes podem ser consideradas diferentes. De fato, a proporção dos associados participantes do PAA é 95\% contra 73\% ( $z=3,41$; prob. $=0,0006)$. Porém, através dos relatos dos agentes-chave entrevistados, ficou claro que a maioria dessas associações estão funcionando irregularmente, não cumprindo seu papel de representar os agricultores junto aos órgãos públicos.

Enfim, diante da realidade apresentada acima, torna-se possível elaborar um resumo das características das variáveis tecnológicas analisadas nesta pesquisa. Assim, dentre as variáveis tecnológicas que apresentaram diferença nas proporções entre os participantes do PAA e os que não participam, têm-se as seguintes: participação em organizações e uso de calcário a um nível de confiança de $99 \%$; uso de análise de solo e tem mecanização com nível de confiança de $95 \%$; e utilização de assistência técnica a um nível de confiança de $90 \%$ (Tabela 1). 
Tabela 1: Teste da presença de diferença estatística das variáveis tecnológicas entre os grupos: participantes do PAA x não participantes.

\begin{tabular}{l|c|c|c}
\hline \multicolumn{1}{c|}{ Variável } & Resultado* & $\begin{array}{c}\text { Estatística de } \\
\text { teste** }\end{array}$ & Probabilidade \\
\hline Faz irrigação & não existe & $-1,550$ & 0,121 \\
\hline Participa em organizações & existe $(99 \%)$ & 3,412 & 0,001 \\
\hline Uso de adubo & não existe & $-0,674$ & 0,501 \\
\hline Uso de calcário & existe $(99 \%)$ & $-4,331$ & 0,000 \\
\hline Uso de agrotóxicos & não existe & 0,747 & 0,455 \\
\hline Uso de análise de solo & existe $(95 \%)$ & $-2,077$ & 0,038 \\
\hline Faz conservação de solo & não existe & 1,280 & 0,200 \\
\hline Tem mecanização & existe $(95 \%)$ & $-2,058$ & 0,040 \\
\hline Tem energia elétrica & não existe & 0,439 & 0,660 \\
\hline Utiliza assistência técnica & existe $(90 \%)$ & $-1,771$ & 0,077 \\
\hline
\end{tabular}

Fonte: Elaborada pelos autores com base nos dados COATER - EMPAER/MT (2009).

* Entre parênteses está o nível de confiança $(90 \%, 95 \%, 99 \%)$ e "existe" indica que há diferença entre os grupos.

**Teste bilateral $\mathrm{Z}$ de proporções, sendo H0: diferença igual a zero; H1: diferença diferente de zero.

Das dez variáveis tecnológicas avaliadas, em cinco (participação em organizações, uso de calcário, uso de análise de solo, mecanização e assistência técnica) existem diferenças entre quem participa e quem não participa do PAA, isto é, quem participa do PAA apresenta resultados diferentes no aproveitamento dessas tecnologias, no trato da terra. A análise das proporções revela, entretanto, que apenas a participação em organizações do grupo do PAA é superior ao do grupo não participante do PAA. Para uso de calcário, uso de análise de solo, ter mecanização e utilização de assistência técnica os resultados revelam uma proporção menor para o grupo do PAA relativamente ao outro, o que é motivo de preocupação para os objetivos de aumento de produtividade e geração de renda, a partir da atividade agrícola.

No entanto, percebe-se que em outras cinco variáveis tecnológicas (faz irrigação, uso de adubo, uso de agrotóxicos, faz conservação de solo, tem energia elétrica) não há diferença entre esses dois grupos.

Analisou-se os produtos com diferença estatística entre a produção dos grupos participantes do PAA e dos não participantes, fazendo um teste estatístico unilateral (teste $\mathrm{t}$ ) de médias, sendo a hipótese nula para produção igual entre grupos (H0: PAA = não PAA) e alternativa para participantes com produção maior que não participantes (H1: PAA> não PAA). 
Estatisticamente (a 90\% de confiança), a produção dos participantes do PAA evidenciaram média acima dos não participantes para abóbora, berinjela, mandioca, milho verde e quiabo. No entanto, alguns produtos analisados não tiveram diferença nas médias, isto é, estatisticamente não foi possível rejeitar que as médias entre os grupos participantes e não participantes do PAA são iguais. São eles: abacaxi, abobrinha, alface, banana maçã, banana da terra, batata doce, berinjela (área), cebolinha, coentro, couve, jiló, limão Taiti, maracujá, maxixe, melancia, melão, pepino, pimenta, pimentão, quiabo (produção), repolho, rúcula, salsa/salsinha, tomate e rapadura.

Portanto, na maioria dos produtos oriundos dos agricultores familiares do município de Cuiabá não há diferença entre a produção média entre os grupos participantes e não participantes do PAA, dessa forma, aceita-se a hipótese secundária de que a produção média entre os grupos participantes e não participantes do PAA não é diferente.

Diante da realidade deparada no Convênio MDS e Prefeitura de Cuiabá, verifica-se a existência do filtro institucional de terceiro nível "tomada de decisão", isto é, quem são os atores que compõem o público-alvo do PAA, quem escolhe os que vão participar do programa, quais os produtos que serão contemplados, e quais as entidades socioassistenciais que irão participar desse processo. Portanto, verifica-se a importância dos atores que compõem o organograma informal de atuação do PAA - Convênio MDS e Prefeitura de Cuiabá, já mencionado anteriormente, pois, a atuação dos conselhos que fazem o controle social é de suma importância, tanto, na determinação dos agricultores que farão parte do convênio, quanto dos produtos que irão compor a proposta, como também, das entidades socioassistenciais que serão beneficiadas pelo Programa.

Com respeito aos resultados apresentados pelos entrevistados (agenteschave do processo), verifica-se que a estrutura de governança (organograma informal) do PAA em Cuiabá (convênio MDS - Prefeitura), a qual seria a responsável pela gestão de funcionamento do programa em nível local, isto é, os atores que deveriam coordenar a execução do programa: SMTDE - Diretoria de Agricultura e Abastecimento, através de seus técnicos, e do conselho (CMDA); SMASDH, através dos conselhos (COMSEA e CMAS), e do Banco de Alimentos; além de representante dos produtores e entidades socioassistenciais, não está funcionando, pois, basicamente, são os técnicos da Diretoria de Agricultura e Abastecimento que determinam quem são os produtores, os beneficiários e os produtos que irão compor o programa.

Logo, percebe-se a importância da adoção conjunta dos conceitos de coordenação e eficiência trabalhados por Azevedo (2000), pois, através da 
existência de uma coordenação de todo o processo de rede do PAA é possível minimizar os custos de transação inerentes ao convênio, isto é, detectar os possíveis filtros institucionais existentes e os possíveis ajustes a serem propostos para sanar tais imperfeições, assim como torna-se provável a adaptação mais rápida às modificações de ambiente e de conflitos que porventura venham a ocorrer entre os atores envolvidos nesse sistema.

Williamson (1985) ressalta a importância da coordenação, como uma característica dos agentes econômicos, onde é possível regular uma transação através do mecanismo da estrutura de governança, isto é, os atores que compõem a rede de atuação do PAA no município de Cuiabá estão atuando coerentemente, estão respaldados formal e legalmente para desempenharem essa função? Percebe-se que não.

Nessa ótica, verifica-se que alguns conselhos diretamente envolvidos nesse processo encontram-se inativos, caso do Conselho Municipal de Desenvolvimento Agrário (CMDA) e outros funcionando precariamente: Conselho Municipal de Segurança Alimentar (COMSEA) e Conselho Municipal de Assistência Social (CMAS). Portanto, tal situação está influenciando negativamente na concretização das metas do PAA no município de Cuiabá, pois deixarm de atuar como agentes de controle social.

$\mathrm{Na}$ sequência, são formuladas algumas sugestões de melhoria para o PAA em Cuiabá:

a) Fortalecer a estrutura de governança do PAA em Cuiabá, isto é, definir formalmente e com clareza quais são os atores chave do processo, suas responsabilidades, a partir daí sugerir mudanças estratégicas para sanar as falhas, fragilidades, filtros detectados na execução do programa;

b) Regularizar e efetivar o funcionamento dos conselhos que são responsáveis, principalmente pelo controle social dos projetos e, também, pela fiscalização e monitoramento na execução dos mesmos, e atualmente, senão todos, a maioria encontram-se atuando de forma precária, sendo que alguns estão inativos;

c) Assim, dentro dessa nova ótica, reativar o atual Convênio (MDS/ Prefeitura de Cuiabá), cujo período de execução está previsto para 2012. Com isso, atuar no sentido de resgatar a confiança dos agricultores familiares no ente municipal; e,

d) Reestruturar o Programa Municipal de Assistência Técnica e Extensão Rural (ATER), criado em 2006, porém, dessa data até a atual não teve atuação concreta junto aos agricultores familiares, devido a vários fatores de ordem política 
e de gestão. Esse ponto é fundamental para que qualquer projeto direcionado ao segmento familiar tenha êxito, pois, só com uma equipe técnica capacitada continuamente, dotada de infraestrutura, autonomia de ação e apoio da instituição, poderá desenvolver seu papel com profissionalismo e responsabilidade junto ao segmento da agricultura familiar.

\section{CONCLUSÕES}

Este trabalho teve por objetivo investigar a operacionalização do Programa de Aquisição de Alimentos (PAA) em Cuiabá - MT. Portanto, seus objetivos específicos foram: avaliar o cumprimento das metas do PAA no município; comparar os resultados produtivos entre produtores participantes do PAA e não participantes; averiguar eventuais dificuldades ou imperfeições na execução do programa; e contribuir com sugestões de melhoria do programa.

No decorrer da elaboração da pesquisa, verificou-se que a meta do PAA convênio 177/2007 entre o MDS e a Prefeitura Municipal de Cuiabá, através da modalidade Compra Direta Local da Agricultura Familiar (CDLAF) com Doação Simultânea - foi considerada cumprida pelos órgãos oficiais, porém, quanto às entidades socioassistenciais, cuja proposta era de beneficiar 175 entidades apenas 83 foram atendidas adequadamente.

No Programa, no âmbito do MDS-CONAB, o município de Cuiabá participou somente com a comunidade Marcolana, cujo projeto contemplava a participação de 27 famílias e o período de execução outubro de 2009 a outubro de 2010, tendo sido prorrogado e até junho de 2011, não tendo sido concluído. Portanto, não foi cumprida a meta inicial.

A pesquisa detectou que na maioria das unidades produtivas oriundas da agricultura familiar do município de Cuiabá não apresentam diferença da produção média entre os grupos participantes e não participantes do PAA.

Quanto à participação em associação, a pesquisa permitiu avaliar que a proporção dos associados participantes do PAA é maior do que os não participantes, isto é, 95\% do participantes do PAA participam de associações, contra $73 \%$ dos não participantes. Porém, nas entrevistas com os agentes-chave do processo, foi detectado que a maioria das associações estão irregulares, considerando sua documentação, assim como também quanto à inadimplência de algumas obrigações legais, não cumprindo, assim, seu papel de representar e facilitar ações junto aos órgãos públicos em benefício dos agricultores familiares.

Não houve diferença estatística entre as proporções dos produtores participantes e não participantes do PAA, em relação a algumas variáveis 
tecnológicas como: uso de irrigação; uso de energia elétrica, uso de agrotóxicos, realização de conservação de solo, e, uso de adubo.

Porém, houve diferença estatística nas proporções entre os participantes do PAA e os não participantes em outras variáveis tecnológicas, a saber: utilização de assistência técnica; participação em organizações; uso de calcário; uso de análise do solo; e uso de mecanização. Porém, apenas a participação em organizações do grupo do PAA foi superior ao do grupo não participante.

Com relação aos filtros institucionais detectados nos programas, tanto na prefeitura quanto da CONAB, percebe-se que não existe uma preocupação maior com quem recebe os alimentos (entidades socioassistenciais), configurando-se como fragilidade do Programa ou filtro institucional de primeiro nível, relacionado ao desenho da política, no caso o convênio MDS-Prefeitura e o contrato MDSCONAB, que se detalha no contrato entre a CONAB e associações descritas.

Com relação à estrutura de governança, tem-se que através dos relatos apresentados pelos entrevistados (agentes-chave do processo), a estrutura de governança (organograma informal) do PAA em Cuiabá (convênio MDS/ Prefeitura), a qual seria a responsável pela gestão de funcionamento do Programa em nível local, isto é, os atores que deveriam coordenar sua execução: SMTDE - Diretoria de Agricultura e Abastecimento, através de seus técnicos e do conselho (CMDA); SMASDH, através dos conselhos (COMSEA e CMAS), e do Banco de Alimentos, além de representante dos produtores e entidades socioassistenciais, não está funcionando, pois, basicamente, são os técnicos da Diretoria de Agricultura e Abastecimento que determinam quem são os produtores os beneficiários, e os produtos que irão compor o Programa.

Quanto à atuação dos conselhos, segundo relato dos entrevistados, a maioria está funcionando precariamente ou, em alguns casos, estão inativos. Isso prejudica a atuação do PAA, pois, trata-se de um segmento imprescindível para o controle social, através do monitoramento na execução do Programa.

Quanto à variável ATER, ocorre outro gargalo a ser resolvido. O Programa existe desde 2006, porém não existe infraestrutura adequada para seu funcionamento, os técnicos estão carentes de qualificação e os recursos financeiros são escassos para tocar o Programa dentro da finalidade proposta, que é de levar aos agricultores familiares conhecimento técnico para elaboração de projetos e técnicas de gestão através de palestras, cursos, seminários, dentre outros.

Outro ponto negativo revelado pela pesquisa foi a interrupção do PAA, no final do ano de 2009, e o não funcionamento no ano de 2010, transformando-se em um pesadelo para os agricultores que continuaram a plantar e não conseguiram a comercialização da produção na sua totalidade, portanto, gerando prejuízo a esses atores. 
Assim, o PAA está sendo executado no município de Cuiabá com algumas dificuldades e/ou imperfeições, devido à forma de atuação da estrutura de governança - atualmente é bastante precária - a qual é responsável pela gestão do programa. Isso foi possível detectar por meio dos questionários e entrevistas com agentes-chave do processo, no segmento rural do município de Cuiabá, especificamente o da agricultura familiar, foco da pesquisa.

Enfim, diante da realidade detectada pela pesquisa, apresentam-se algumas sugestões para o PAA executado no município de Cuiabá: fortalecer a estrutura de governança do PAA em Cuiabá; regularizar a situação dos conselhos; que seja reativado o atual convênio (MDS/Prefeitura de Cuiabá), cujo período de execução está previsto para 2012 e reestruturar o Programa Municipal de ATER, criado em 2006.

\section{REFERÊNCIAS}

ABRAMOVAY, R. O capital social dos territórios: repensando o desenvolvimento rural. Economia Aplicada, Porto Alegre, v. 4, n. 2, p. 379-397, abr./jun. 2000.

AZEVEDO, P.F. de. Nova Economia Institucional: referencial geral e aplicação para a agricultura. Agricultura em São Paulo, v. 47, n. 1, p. 33-52, 2000.

BRASIL. Termo de Convênio no 177/2007 que entre si celebram a União (MDS) e a Prefeitura Municipal de Cuiabá para implantação do Programa de Aquisição de Alimentos (PAA). Brasília, 2007.

Ministério de Desenvolvimento Social e Combate à Fome. Rede de atuação do PAA. Brasília, s.d. Disponível em: $<$ http://www.mds.gov.br $>$. Acesso em: 25 abr. 2011.

BRAVO, J. R. B.; ROSSI, F. Como tornar seu sítio lucrativo. Viçosa: CPT, 2002. 188 p.

CHMIELEWSKA, D. The social significance of the policy process: the case of the program of acquisition of food from family agriculture (PAA) in Araraquara, São Paulo State, Brazil. 2009. 138f. Dissertação (Mestrado) Universidade de Wageningen, Holanda, 2009.

CHMIELEWSKA, D.; SOUZA, D. Market alternatives for smallholder farmers in food security initiatives: lessons from the Brazilian Food Acquisition Programme. Brasília: IPC-UNDP, jun. 2010. (Working Paper, n. 64). 
ChMielewskA, D.; SOUZA, D.; LOURETE, A. A. O Programa de Aquisição de Alimentos da Agricultura Familiar (PAA) e as práticas dos agricultores participantes orientadas ao mercado: estudo de caso no estado de Sergipe. Brasília: IPEA, set./2010. (Texto para Discussão, n. 1510)

COMPANHIA NACIONAL DE ABASTECIMENTO. Relatório de Gestão 2009. Superintendência Regional de Mato Grosso. SEGEO/CONAB/SUREG/ MT, 2010.

DELGADO, G. C.; CONCEIÇÃO, J. C. P. R.; OLIVEIRA, J. J. Avaliação do Programa de Aquisição de Alimentos da Agricultura Familiar (PAA). Brasília: IPEA, dez./2005. (Texto para Discussão, n. 1145)

EMPRESA MATO-GROSSENSEDE PESQUISA, ASSISTÊNCIA TÉCNICA E EXTENSÃo RURAL. Programa Mato Grosso Auto Suficiente em Frutas, Legumes e Verduras - FLV's - Território da Cidadania Baixada Cuiabana. Pesquisa em andamento desde 2209.

GARCIA, R. C. Mato Grosso (1800-1840): crise e estagnação do projeto colonial. 2003. Tese (Doutorado em História Econômica) - Faculdade de Filosofia, Letras e Ciências Humanas, Universidade de São Paulo, 2003.

IBGE. Censo Agropecuário 2006. Rio de Janeiro, 2009. Disponível em: <http:/ /www.sidra.ibge.gov.br>. Acesso em: 10 out. 2010.

MCCLAVE, J. T.; BENSON, G.; SINCICH, T. Estatística para administração e economia. São Paulo: Pearson Prentice Hall, 2009.

MILANI, C.; SOLÍNIS, G. Pensar a democracia na governança mundial: algumas pistas para o futuro. In: MILANI, C.; ARTURI, C.; SOLÍNIS, G. (Orgs.). Democracia e governança mundial - que regulações para o século XXI. Porto Alegre: UFRGS; UNESCO, 2002. p.266-291.

MULLER, A. L. A construção das políticas públicas para a agricultura familiar no Brasil: o caso do Programa de Aquisição de Alimentos. 2007. $128 \mathrm{f}$. Dissertação (Mestrado em Desenvolvimento Rural) - Faculdade de Ciências Econômicas, Universidade Federal do Rio Grande do Sul, Porto Alegre, 2007.

MUNDO NETO, M.; SOUZA FILHO; H. M. Problemas do Crédito Rural sob a ótica da Nova Economia Institucional. Revista de Ciências Gerenciais, Campinas, v. 9, p. 92-99, 2005.

RIO GRANDE DO SUL. Projeto para hortas comunitárias. Porto Alegre: SJDS-RS, s/d. Disponível em:<http://www.sjds.rs.gov.br $>$ Acesso em: 10 jun.2010. 
SCHMITT, C. J. Aquisição de alimentos da agricultura familiar: integração entre política agrícola e segurança alimentar e nutricional. Revista de Política Agrícola, Brasília: Embrapa/MAPA, v. 14, n. 2, abr./maio/jun. 2005.

VEIGA, J. E. Do crescimento agrícola ao desenvolvimento rural. In: CASTRO, A. C. (Org.). Desenvolvimento em debate. Rio de Janeiro: Ed. Mauad; BNDES, 2002. v. 2, p. 383-409.

WILLIAMSON, O. E. The economic institutions of capitalism. New York: The Free Press. 1985.

ZEZZA, A.; LLAMBÍ, L. Meso-economic filtres along the policy chain: understanding the links between policy reforms and rural poverty in Latin America. Roma/Caracas: ESA-FAO, 2001. Disponível em: < http://www.fao. org/docrep/007/ae027e/ae027e00.HTM>. Acesso em: 01 ago. 2009. 
